\title{
Overheating and hospitals - what do we know?
}

\author{
Catriona Carmichael ${ }^{1}$, Graham Bickler ${ }^{1}$, Sari Kovats ${ }^{2}$, David Pencheon ${ }^{3}$, Virginia Murray ${ }^{1}$, \\ Christopher West ${ }^{4}$, Yvonne Doyle ${ }^{5}$
}

1. Health Protection Agency, London, UK. 2. Faculty of Public Health and Policy, London School of Hygiene and Tropical Medicine, London, UK. 3. NHS Sustainable Development Unit, Fulbourn, UK. 4. Environment Agency, Wallingford, UK. 5. NHS South of England, Newbury, Berkshire, UK.

Correspondence: Catriona Carmichael. Address: Extreme Events and Health Protection Section, Centre for Radiation, Chemicals and Environmental Hazards, Health Protection Agency, 151 Buckingham Palace Road, London SW1W 9SZ, UK. E-mail: katie.carmichael@hpa.org.uk

Received: August 29, 2012

DOI : $10.5430 /$ jha.v2n1p1
Accepted: October 9, 2012

Online Published: November 5, 2012

\section{Abstract}

Heatwaves have well described impacts on human health and wellbeing. Heatwaves also have impacts on hospitals; patients, visitors, equipment, medication and information technology systems have all been affected or compromised during episodes of extreme heat. High indoor temperatures are also of concern for the comfort, efficiency, and occupational health of staff. The Heatwave Plan for England describes actions to prepare for and be taken in the event of a heatwave. Advice for a hospital is so far limited and not evidence based. In this paper, we review what is currently known about the impacts of heatwaves on hospitals and identify several important information gaps. Improved responses to hot weather could improve patient care and staff comfort. If seen as part of a wider approach to sustainability, proper planning will also enable hospitals to reduce health care costs, increase efficiency and meet carbon reduction targets.

\section{Key words}

Heatwave, Hospitals, Overheating, Climate change, Health, Indoor temperature, Sustainability

\section{Introduction}

Europe has experienced major heatwave events in recent decades - notably the 2003 event in France and Western Europe and the 2010 heatwave in Russia and Eastern Europe. Both events were associated with significant impacts at the population level, as well as impacts on infrastructure, energy production, transport, agriculture, and service delivery. Many problems were reported in hospitals in August 2003, including equipment failures. The high indoor temperatures caused staff and patient discomfort and distress ${ }^{[1]}$ (see Table 1).

The Intergovernmental Panel on Climate Change (IPCC) has concluded that, based on observations and climate model projections, heatwaves are very likely to increase in their frequency and intensity in the near future ${ }^{[2]}$. The UK Climate Change Risk Assessment (CCRA) suggested that local healthcare provision might be affected if temperatures in hospital wards are not effectively controlled, affecting both patient recovery and the performance of staff ${ }^{[3]}$.

In this paper, we briefly review what is currently known about the impacts of heatwaves on hospitals with respect to inpatients, staff, infrastructure and equipment. We will then discuss the context of these impacts with respect to NHS 
sustainable development targets more generally, and show how interventions to protect patients and staff, will have co-benefits in terms of efficiency, reduced costs and the environment.

Table 1. Reported effects of 2003 heatwave in UK hospitals

- $\quad$ Failure of a freezer destroying human specimen samples;

- Staff became unwell from working in the heat;

- $\quad$ Patients became dehydrated;

- Operations were cancelled due to IT equipment failure;

- Laboratory work halted because machines failed in the heat;

- $\quad$ Electricity supplies being overworked due to portable air conditioning units being used by staff. Source: Based on newspaper and media reports ${ }^{[1]}$.

\section{I mpacts on In-patients}

Ambient heat affects some individuals more than others, depending on their personal exposures and their susceptibility ${ }^{[4]}$. Population-based studies have indicated that a wide range of chronic conditions can increase risk to heat related morbidity and mortality ${ }^{[5]}$. Those at increased risk from heat-related death and heat injury include older people, the very young, those with chronic diseases (particularly cardiovascular, respiratory, diabetes and muscular-skeletal conditions), those with mental health conditions ${ }^{[6]}$ and those taking particular medications that impair thermoregulation ${ }^{[7]}$. Older people have impaired thermal perception, as well as limited thermoregulation due to the ageing process. Hospitals, by their very nature, are places where vulnerable people are concentrated and can spend considerable time.

The heatwave of 2003 was responsible for over 2000 deaths in England and Wales ${ }^{[8]}$, mostly in the elderly. The direct effect on in-hospital mortality rates has not yet been formally investigated. The heatwave was associated with a short term increase in emergency hospital admissions, particularly in London. In England, it has been shown that persons in nursing homes are at much higher risk of heat related mortality than the general population ${ }^{[5]}$. Many hospitals, like nursing homes are not air conditioned in England and Wales ${ }^{[9]}$.

England's most severe heatwave occurred in 1976. A study in Birmingham, England, found that in-patient death rates increased during that event ${ }^{[10]}$. Evidence from France has also shown that deaths rates in wards that were not air conditioned increased during extreme hot weather ${ }^{[11]}$. A more detailed study of in-hospital deaths in Italy found that the risk of mortality during hot weather was increased by hospital ward type, advanced age and being unmarried ${ }^{[12]}$. Patients in general medical wards were at higher risk than patients in intensive care . Patients with a history of admission of mental illness or cerebrovascular disease were also found to have higher rates of heat-related death ${ }^{[12]}$.

High temperatures are associated with acute increases in emergency hospital admissions, particularly for respiratory causes $^{[13,14]}$. Currently there is no systematic evaluation of visits to emergency departments and overall workload during heatwaves.

Some specific risks to hospital patients have been identified - for example, the use of plastic mattresses for immobile patients and physiotherapy routines during hot periods of the day ${ }^{[15]}$. The use of fans in hospitals has been debated. A recent Cochrane systematic review found no evidence regarding their effectiveness in preventing adverse health impacts during heatwaves ${ }^{[16]}$.

Kovats and West reported that emergency departments have experienced problems during heatwaves and like other areas within the hospital need to be adequately prepared for such events ${ }^{[1]}$. At the moment under the Heatwave plan for England, warnings are cascaded to Emergency Departments to help them to manage staff levels ${ }^{[6]}$. 
Anecdotal evidence from the 2003 heatwave in the UK, such as that presented in Table 1 shows the potential risk to patient safety from heatwaves.

There is a wide range of evidence, anecdotal and theoretical reasons to be concerned about the impacts of heat in hospitals on patient and staff wellbeing. However, in several important areas, the range of evidence currently available demonstrates that more research is required so that we are able to understand the risks better and can develop evidence based responses to better protect the health of those in hospitals.

\section{I mpacts on staff}

Heat is a well described occupational hazard ${ }^{[17]}$. Persons who are physically active in high temperatures are at increased risk of heat injury. Occupational studies show that at high ambient temperatures workers experience reduced cognitive ability and experience an increased risk of accidents ${ }^{[17]}$.

Problems in hospitals during the 2003 event, including impacts on staff are highlighted in Table 1. Issues such as the timing of shifts and staff uniforms may need to be adjusted. The balance of temperature within clinical areas needs careful consideration due to the diverse range of people and activities that are often undertaken in one place. Whilst patients who are relatively inactive need to be kept warm to aid their on-going care, comfort and recovery, the needs of the active staff who wear uniforms must also be met by keeping them cool. Uniforms themselves pose a particular challenge in successfully balancing the needs of adequate infection control, personal protection and protecting the individual from excess heat gain. Experience from departments such as Special Care Baby Units where high temperatures are the norm may be useful.

\section{I nfrastructure and design}

There has been increasing interest in overheating in hospital wards with several research projects currently underway through the Design \& Delivery of Robust Hospital Environments in a Changing Climate programme (DeDeRHECC). This programme aims to "investigate the design and delivery of economical and practical strategies for the adaptation of the NHS Retained Estate to increase its resilience to climate change whilst meeting the challenging carbon reduction goals and performance requirements of the NHS” ${ }^{[18]}$. Amongst its work packages, it is currently investigating temperature control in hospital buildings, the resilience of existing structures to future weather conditions and the potential possibilities of sustainable, low energy refurbishments to existing hospital buildings ${ }^{[18]}$. Other studies have investigated how building design, ward layout, hospital ventilation and refurbishing of traditional "Nightingale" wards can influence the potential to overheat ${ }^{[19,20]}$. Much hospital infrastructure in England and Wales is old, and wards in these buildings can have indoor environments (including temperatures) that can be much more efficiently and intelligently and passively controlled to ensure patient and staff comfort ${ }^{[18]}$. These projects have not investigated the impacts on patients or staff.

High temperatures can also affect the efficacy of drugs ${ }^{\text {[21] }}$. During the heatwave of 2003 in England, temperatures in drug cupboards and doctor's bags were reported to increase to 35 and $40^{\circ} \mathrm{C}^{[22]}$.

Electrical equipment and information technology (IT) systems provide an ever increasing role in acute care services. Protection against heat is vital to prevent the breakdown of equipment and computer systems, while the waste heat generated by such equipment may be a significant part of the cooling load of the building. All cooling systems are vulnerable to failure when operating near the upper temperature limit for which they were designed. The consequences of failure are then at their most severe. This can be addressed at the procurement stage by specifying a system with greater capacity and enhanced redundancy. 
Local assessment of individual hospitals would assist in identifying each hospital's resilience to heatwaves, an understanding of their cooling systems including building design for ventilation and use of fans by individual patients to air conditioning temperature controls. In hot and humid countries, there has been research into patient-operated fans which are an easy, cost effective way of maintaining patient comfort and safety ${ }^{[23]}$. Looking at the potential for implementing similar devices within the UK would be beneficial.

Although some published literature on this topic is available, a greater understanding on the impact of overheating in hospitals is required to base future planning, preparedness and response to heatwaves. This work would contribute to the safer hospitals initiative of the World Health Organisation who state that improving resilience of hospitals to disasters is not only of economic importance but also a social, moral and ethical imperative ${ }^{[24]}$.

\section{Heatwave plan for England}

The Heatwave Plan for England has been produced by the Department of Health since 2004, and more recently, a Cold Weather Plan has also been published ${ }^{[6,25]}$. The Heatwave Plan aims to raise both public and professional awareness of the health impacts of severe heat ${ }^{[6]}$. The Plan's purpose is to enhance resilience in the event of a heatwave and highlight actions to be taken with those who are vulnerable to the effects of heat. The Plan is an important component of national emergency planning.

The Heatwave Plan recommends that hospital staff undertake a number of actions to increase resilience and protect their patients and staff against the adverse effects of heat during severely hot weather. As with all emergency plans, NHS and other health care facility managerial staff have a responsibility to ensure actions are taken and monitored regardless of competing priorities.

Suggested activities include:

- Regular temperature checks during periods of hot weather and development of cool rooms where the temperature is kept below $26^{\circ} \mathrm{C}$.

- Move vulnerable patients to cooler rooms for periods of the day to achieve respite and relief from the heat, if feasible.

- Keep vulnerable patients who cannot be moved cool by cool sponge baths, ventilating rooms and keeping sunlight out by the use of curtains.

Hospitals are advised to have business continuity plans updated prior to the summer months. This is because in the event of a severe heat event, extra staff and operational capacity may be required ${ }^{[26]}$. Ensuring there are sufficient stocks of fresh water and ice available and that hospital staff are aware of the harmful effects of heat on health is a priority. Hospitals should also consider systematic responses to prolonged heatwaves in their risk registers to ensure that systems are in place that can deliver some of the known proactive preparations and reactive responses. Some hospitals in England refer to these approaches in their risk registers and/or their sustainable development management plans (SDMPs) ${ }^{\text {[26] }}$.

Hospitals should be aware of how to receive alerts via their management and local public health services (or equivalent) and should have systems in place of how to disseminate and cascade the alerts so the actions outlined in the Heatwave Plan are undertaken in a timely manner. There is very little time between the onset of a heatwave event and the onset of morbidity and mortality outcomes (0 to 2 days) ${ }^{[6]}$. This should impress on hospital staff the speed at which interventions are required in order to successfully protect patients. 
Regular revisions and stakeholder engagement has ensured that the Heatwave Plan for England remains as up to date and evidence based as possible. However, it is clear that more work into building the appropriate responses to heatwaves is required including better research to build the evidence on identification of indoor heat thresholds in hospitals as has been discussed in domestic settings ${ }^{[27]}$. At present, the threshold of $26^{\circ} \mathrm{C}$ is cited but further research would be of significant value due to the currently weak evidence base behind this. Other areas include which patients or wards are the most vulnerable to its effects. Further research would help achieve the aims and objectives of reducing heat related morbidity, mortality and pressures on the health care system within hospitals.

\section{Sustainable development and adapting to heatwaves}

The Heatwave Plan for England identifies the need to reduce indoor temperatures. A range of passive interventions to cool buildings has been outlined in the Heatwave plan and could be applied to the structures and surrounding estates of hospitals to prevent overheating ${ }^{[6]}$. Increased green spaces, trees and plants have been suggested as ways of preventing overheating and avoiding the need for excessive air conditioning. This would also help Trusts to meet their NHS Carbon targets as set out by national policy and research units such as the NHS sustainable development unit ${ }^{[28]}$. Active programmes in this area include the "NHS Forests: Growing Forests for Health" project which is working to increase access to green space around NHS estates in the UK ${ }^{[29]}$.

Private Finance Initiative (PFI) contracts to build and run NHS estate, originally with the purpose of shifting public financial risk to the private sector because of their skill in managing such risks, do not seem to have managed to transfer public climate risks in the same way. It is unclear whether this is due to the lack of ability to define, cost or manage these apparently uncertain risks, to an inability to frame appropriate contractual arrangements, or due to uncomfortably high costs. Firth identified some of the issues around PFI and climate adaptation, but more work is needed to realise the adaptation potential of this mechanism ${ }^{[30]}$.

Air conditioning contributes to increased greenhouse gas emissions. It also uses considerable amounts of energy which could put extra pressure on the electricity grid system and be very expensive to run during periods of high heat. An additional risk of whole-hospital air conditioning is the impact of catastrophic failure of the system. Benefits of reducing the need for air conditioning through the increasing of green space include not only the money saved in operational costs due to lower electricity use, but the positive impact that green spaces have on the health of staff, visitors and patients ${ }^{[7,31]}$. However, there will continue to be a need for the use of independent air conditioning systems in certain departments of hospitals that are unable to function adequately with alternative systems and whose patients are particularly vulnerable to heat.

\section{Conclusion}

Hospitals offer a range of unique heat-health challenges due to their vulnerable populations, the wide range of different activities that occur within them, a workforce that functions 24 hours a day, the storage of medications and the large amount of essential equipment vulnerable to heat.

However, it is clear from the literature that there is a considerable need for further evidence to inform actions to protect the health of those who are admitted to or work in hospitals. A better understanding on the health impacts of overheating and hospitals alongside quantification of the current problem in England would aid development of cost-effective policies that would improve efficiency and also protect health. Although some investigations have been undertaken on overheating in hospital buildings, there is little information on the impacts on inpatients, staff, IT equipment, drug efficacy and visitors. This would facilitate sharing what is currently known and assist in identifying where the most serious gaps in evidence exist. Such a literature review would be of considerable value in England and, we believe, internationally. 
Finally, we believe that hospitals are better at planning to respond to emergencies including heatwaves than considering holistic longer term resilience including design improvements for climate change adaptation and sustainability. We therefore need specific research projects to inform policy on the wider sustainability agenda noting that this could also deliver co-benefits to Trusts such as financial savings.

\section{Acknowledgements}

The authors would like to thank Dr. Alistair Fair for his advice and commentary.

\section{References}

[1] Kovats, R.S. and C. West. Heat waves: health impacts and acute responses. Chemical Hazards and Poisons Report. 2005 May; 20-22.

[2] IPCC. Managing the Risks of Extreme Events and Disasters to Advance Climate Change Adaptation. A Special Report of Working Groups I and II of the Intergovernmental Panel on Climate Change, Cambridge, UK, and New York, NY, USA: Cambridge University Press. 2012; 582.

[3] Hames D, Vardoulakis S. Climate Change Risk Assessment for the Health Sector 2012 Report for the UK Climate Change Risk Assessment [Internet]. Available from: http://randd.defra.gov.uk/Document.aspx?Document=CCRAfortheHealthSector.pdf.

[4] Kovats, R.S. and S. Hajat. Heat stress and public health: a critical review. Annu.Rev.Public Health. 2008; 29 : 41-55. PMid:18031221 http://dx.doi.org/10.1146/annurev.publhealth.29.020907.090843

[5] Hajat, S., R.S. Kovats, and K. Lachowycz. Heat-related and cold-related deaths in England and Wales: who is at risk? Occupation Environ Med. 2007; 64: 93-100. PMid:16990293 http://dx.doi.org/10.1136/oem.2006.029017

[6] Department of Health 2012(a). National Heatwave Plan for England: Protecting Health and reducing harm from severe heat and heatwaves. London: Department of Health.

[7] Department of Health National Heatwave Plan for England: Making the Case: The impact of heat on health: now and in the future. 2012(b), London: Department of Health

[8] Johnson H, RS Kovats, G R McGregor, J R Stedman, M Gibbs, H Walton, L Cook, E Black. The impact of the 2003 heatwave on mortality and hospital admissions in England. Health Statistics Quarterly. 2005; 25: 6-11. PMid:15804164

[9] Short C A, Lomas K.J., Renganathan G and Fair, A. J. Building resilience to overheating into 1960’s UK hospital buildings within the constraint of the national carbon reduction target: Adaptive strategies Building and Environment. 2012; 55: 73-95. http://dx.doi.org/10.1016/j.buildenv.2012.02.031

[10] Ellis, F.P, Prince H.P., Lovatt G and Whittington R.M. Mortality and morbidity in Birmingham during the 1976 heatwave. Q J Med. 1980; 49(193): 1-8. PMid:7433626

[11] Ferron, C., Ferron C, Trewick D, Le Conte P, Batard ER, Girard L and Potel G. Heat stroke in hospital patients during the summer 2003 heat wave: a nosocomial disease. Presse Medicale. 2006; 35(2): 196-199. http://dx.doi.org/10.1016/S0755-4982(06)74553-5

[12] Stafoggia, M, Forastiere F, Agostini D, Caranci N, de'Donato F, Demaria M, Michelozzi P, Miglio R, Rognoni M, Russo A and Percucci CA. Factors affecting in-hospital heat-related mortality: a multi-city case-crossover analysis. Journal of Epidemiology and Community Health. 2008; 62(3): 209-215. PMid:18272735 http://dx.doi.org/10.1136/jech.2007.060715

[13] Kovats RS, S Hajat, Wilkinson P. Contrasting patterns of mortality and hospital admissions during hot weather and heat waves in Greater London, UK. Occupational and Environmental Medicine. 2004; 61(11): 893-898. PMid:15477282 http://dx.doi.org/10.1136/oem.2003.012047

[14] Michelozzi P, Accetta G, De Sario M, D'Ippoliti D, Marino C, Baccini M, Biggeri A, Anderson HR, Katsouyanni K, Ballester F, Bisanti L, Cadum E, Forsberg B, Forastiere F, Goodman PG, Hojs A, Kirchmayer U, Medina S, Paldy A, Schindler C, Sunyer J, Perucci CA. PHEWE Collaborative Group. Am J Respir Crit Care Med. 2009 Mar 1; 179(5): 383-9. Epub 2008 Dec 5. PMid:19060232 http://dx.doi.org/10.1164/rccm.200802-217OC

[15] Lowe D, Ebi K, Forsberg B. Heatwave Early Warning Systems and Adaptation Advice to Reduce Human Health Consequences of Heatwaves. Int. J. Environ. Res. Public Health. 2011; 8: 4623-4648. PMid:22408593 http://dx.doi.org/10.3390/ijerph8124623

[16] Gupta S, Carmichael C, Simpson C, Clarke MJ, Allen C, Gao Y, Chan EYY, Murray V. Electric fans for reducing adverse health impacts in heatwaves. Cochrane Database of Systematic Reviews. 2012; Issue 7. Art. No.: CD009888. http://dx.doi.org/10.1002/14651858.CD009888.pub2

[17] Kjellstrom T, Holmer I, Lemke B. Workplace heat stress, health and productivity - an increasing challenge for low and middle-income countries during climate change Glob Health Action. 2009; 2: 2047. 
[18] DeDeRHECC (2012) Design and Delivery of Robust Hospital Environments in a Changing Climate [Internet]. Summary of publications. Available from: http://www-edc.eng.cam.ac.uk/robusthospitals/publications.html.

[19] Lomas KJ, Giridharan R, Short CA and Fair AJ. Resilience of 'Nightingale' hospital wards in a changing climate BUILDING SERV ENG RES TECHNOL. 2012; 33: 81-103.

[20] Lomas KJ, Yingchun Ji. Resilience of naturally ventilated buildings to climate change: Advanced natural ventilation and hospital wards Energy and Buildings. 2009; 41: 629-653.

[21] WHO (2009) Improving Public Health Responses to Extreme Weather/Heat-Waves -EuroHEAT. Meeting Report. Bonn, Germany, 22-23 March 2007 WHO, Rome.

[22] Crichton B. Keep in a cool place: exposure of medicines to high temperatures in general practice during a British heatwave. J R Soc Med. 2004; 97: 328-329. PMid:15229258 http://dx.doi.org/10.1258/jrsm.97.7.328

[23] Lomas KJ. and Giridharan R. 'Thermal comfort standards, measured internal temperatures and thermal resilience to climate change of free-running buildings: a case-study of hospital wards', Building and Environment. 2012; 55, 57-72. http://dx.doi.org/10.1016/j.buildenv.2011.12.006

[24] WHO, (2012) Humanitarian Health Action: Hospitals safe from disasters. Geneva: World Health Organization.

[25] Department of Health 2012(c) National Cold Weather Plan for England: Protecting Health and reducing harm from severe winter weather. London: Department of Health.

[26] NHS, Sustainable Development Management Plans (SDMP) [Internet]. 2012(a). Available from: http://www.sdu.nhs.uk/sd_and_the_nhs/sd-governance/sdmp.aspx.

[27] Anderson M, Carmichael C, Murray V, Dengel A, Swainson M. Defining indoor heat thresholds for health in the UK [Internet]. Perspect Public Health. 2012; July. Available from: http://rsh.sagepub.com/content/early/2012/07/25/1757913912453411.abstract.

[28] NHS, Sustainable Development Governance 2012(b) [Internet]. Available from: http://www.sdu.nhs.uk/sd_and_the_nhs/sd-governance.aspx.

[29] NHS Forest (2012) NHS Forest: Growing Forests for Health [Internet]. Available from: http://nhsforest.org/.

[30] Firth, J., 2005. Climate change risks for PFI/PPP projects [Internet]. Available from: http://www.acclimatise.uk.com/index.php?id=9\&section=resources\&resource=10.

[31] Ulrich RS. View through a window may influence recovery from surgery. Science. 1984; 224 (4647): 420-421. PMid:6143402 http://dx.doi.org/10.1126/science.6143402 